\title{
Las relaciones sociales débiles constituyen un factor de riesgo para la salud
}

\author{
Weak social relationships are a risk factor for health
}

\section{Objetivos}

Determinar la magnitud de la influencia de las relaciones sociales sobre el riesgo de mortalidad.

\section{Fuentes de datos, selección de los estudios y extraccion} de los datos

De 11.124 trabajos publicados entre 1900 y 2007 identificados en bases de datos electrónicas, sólo fueron incluidos los escritos en inglés y que hubieran reportado datos cuantitativos sobre mortalidad. Fueron excluidos los que incorporaron datos de mortalidad por suicidio o lesiones; los que consideraron "apoyo social" a una intervención provista en el marco del propio estudio; aquellos en los que el soporte social analizado había sido no humano o no había sido brindado al caso en estudio sino a terceros; los que sólo reportaron datos censales y/o contaban sólo con el estado civil como único indicador de apoyo social.

\section{Resultados Principales}

Fueron analizados 148 estudios que habían incluido 308.849 casos con un promedio de edad de 63,9 años (49\% mujeres y $51 \%$ varones, la mitad norteamericanos y los demás europeos, asiáticos y australianos). El $60 \%$ de los estudios había incluido pacientes de la comunidad, $24 \%$ de atención ambulatoria, y $16 \%$ de internación. El seguimiento promedio fue de 7,5 años (rango tres meses a 58 años) y un de $29 \%$ de los participantes murieron dentro del período de seguimiento correspondiente a cada estudio. Se extrajo información demográfica, del estado de salud, de enfermedades preexistentes, del estilo de vida, de las causa de muerte y de los aspectos de las relaciones sociales evaluadas, que fueron clasificados básicamente como estructurales y funcionales (o como combinaciones de los mismos).

- Aspectos funcionales: 1) de apoyo recibido (emocional, de información o material); 2) de percepción de apoyo social (idem

\author{
Holt-Lunstad J y col. PLoS Med, 2010, 7(7): e1000316.
}

anteriores); 3) de soledad (sentimientos de aislamiento, de apatía o de no pertenencia).

- Aspectos estructurales: 1) de situación de pareja, 2) de redes sociales (ej. número de contactos en el mundo real); 3) de integración (grado de participación en diversas relaciones y/o actividades, sentido de comunidad e identificación con algún rol social); 3) de convivencia (vivir solo vs. con otro); 4) de aislamiento social (falta generalizada de relaciones sociales y de comunicación, de participación y/o ausencia de confidentes); 5) medidas complejas de integración con varios componentes de los anteriores.

Los individuos con adecuadas relaciones sociales evidenciaron una probabilidad de supervivencia un $50 \%$ mayor $(\mathrm{OR}=1,50$; IC95\% 1,42 a 1,59) que aquellos cuyas relaciones sociales fueron deficientes o insuficientes, que se mantuvo constante, luego de ajustar por edad, sexo y diagnóstico, etc., (lo que sugiere que la asociación entre las relaciones sociales y la mortalidad sería general, y no limitada a subgrupos). Las diferencias fueron significativas $(p<0,001)$ para todos los aspectos de las relaciones sociales considerados, y la asociación fue más fuerte con las medidas complejas de integración $(\mathrm{OR}=1,91$; IC95\% 1,63 a 2,23 ) y menor con los indicadores binarios (OR $=1,19$, IC $95 \% 0,99$ a 1,44$)$.

\section{Conclusiones}

Una adecuada relación social se asocia una mayor supervivencia siendo la magnitud de este efecto comparable a dejar de fumar y superando muchos factores de riesgo de mortalidad conocidos (p. ej.: obesidad, sedentarismo).

Palabras claves: factores de riesgo, relaciones sociales, integración social, determinantes de la salud.

Key words: risk factors, social relationships, social integration, determinants of health.

Fuente de financiamiento: Departamento de Gerontología de la Universidad Brigham Young, y TP Industrial Inc.

\section{Comentario}

La influencia de las relaciones sociales y en un sentido más amplio de los estímulos psicosociales en la salud han sido motivo de investigación en el campo de la sociología médica desde hace al menos unos cincuenta años ${ }^{1}$. La complejidad conceptual del problema ${ }^{2,3}$ y las dimensiones subjetivas involucradas plantean retos metodológicos de importancia, que se ponen en evidencia también en el presente trabajo. Sin embargo, las conclusiones resultan robustas y congruentes con la observación en la práctica clínica. Aunque quizás no pensábamos que el riesgo de mortalidad pudiera ser mayor que el de la obesidad o el sedentarismo.

Para el médico en su práctica cotidiana, la existencia del soporte vincular de sus pacientes debería ser otro factor de riesgo a relevar, recordando que la información, el afecto y la orientación a la resolución de problemas prácticos son intervenciones posibles y a su alcance.
Por otro lado y desde la perspectiva institucional y de la Salud Pública se hace evidente la necesidad y la importancia de desarrollar dispositivos de intervención multidisciplinarios para brindar apoyo a las personas enfermas de cualquier grupo etáreo en situación de soledad o aislamiento.

\section{Conclusiones del comentador}

Los médicos deben valorar la existencia y calidad de los vínculos sociales de sus pacientes, y las instituciones proveer los dispositivos de intervención que permitan fortalecer recursos sociales existentes, y brindar o facilitar asistencia básica tanto a los pacientes como al equipo de salud.

Javier Vilosio [ Departamento de Salud Pública del Instituto Universitario Hospital Italiano de Buenos Aires. javier.vilosio@ hospitalitaliano.org.ar ]

Vilosio J. Las relaciones sociales débiles constituyen un factor de riesgo para la salud. Evid Act Pract Ambul 14(2) 49. Abr-Jun 2011. Comentado de: Holt-Lunstad $\mathbf{J}$ y col (2010) Social Relationships and Mortality Risk: A Meta-analytic Review. PLoS Med 7(7): e1000316. doi:10.1371/journal.pmed.1000316 PMID: 20668659.

\section{Referencias}

1. Cassel J (1975) The contribution of the social environment to host resistance. The fourth Wade Hampton Frost Lecture. American Journal of Epidemiology Vol. 104 , N². 2. Montero y Lopez Lena M y col. (2001) La soledad como fenómeno psicológico: un análisis conceptual. Salud Mental, Vol. 24, No. 1, febrero.

3. Castro R y col. (1997) La investigación sobre apoyo social en Salud: situación actual y nuevos desafíos. Revista de Saude Pública vol. 31, num. 4, agosto. 